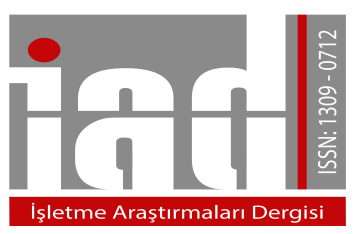

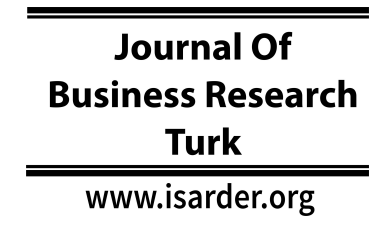

\title{
Empirical Study on the Determinants of Social Media Adoption By Turkish Small And Medium Enterprises
}

\author{
Yakup AKGÜL \\ Alanya Alaaddin Keykubat University \\ Faculty of Business Administration \\ Alanya, Antalya, Turkey \\ orcid.org/0000-0001-5344-4359 \\ yakupakgul@gmail.com
}

\begin{abstract}
Social media has become a major issue for companies. Nonetheless, few studies specifically researched the determinants of social media adoption and the barriers against it, at a small and medium entreprises (SMEs) level aspect. This study addresses the gap by focusing in furthering the theory in social media adoption at SMEs level. Small to Medium Enterprises (SMEs) are not well equipped to use Social Media (SM) and struggle to utilise its full potential in the context of adding value to the business. The main aim of this study is to investigate the adoption and use of social media by Turkish small and medium enterprises, on the basis of Technology Acceptance Model (TAM), Network Externality, and Innovation Diffusion Theory (IDT) models by adding the related constructs. The research model is empirically assessed SMEs' adoption behavior of the social media using a primary data set of 473 users of social media gathered from a web-based questionnaire survey. Partial Least Squares (PLS) method is a variance based Structural Equation Model (SEM) used for the analyse of the data in order to reveal the relationship of the attitudes of SMEs regarding social media and to evalaute the harmony of the model. The results demonstrate that the revised social media model proposed in this study supports all the hypotheses of social media usage behavior.
\end{abstract}

Keywords: Social media, Tehnology Acceptance Model (TAM), Structural Equation Model (SEM), Partial Least Squares (PLS), Small to medium sized enterprises

\section{Introduction}

In recent years, social media (SM) has penetrated people's daily life with amazing rapidity to become a significant social platform for web based communication as a new communication systems between people and organizations, which is probably the most influential development the origination of the social media (SM) (Correa et al., 2010; Hoffman and Novak 1996; Powell, 2009; Tapscott, 2008; Willis, 2008; Zhou, 2011). Theoretically, SM can be accepted as another class of information technology (IT), a 
cluster of people connected for a specific reason, given that they unify a shift of new capacities enabling them to arise from the group and adopt their own particular space in the web applications (Kane et al., 2012; Ryan, 2011a; Ryan, 2011b). SM has conduced to augmenting lists of connections between users sharing mutual concerns and to the constitution of online communities and digital social networks. SM is considered of tremendeous substantial both for individuals and organizations, since they reinforce the retainance of existing social ties and the disposition of new connections between both users and organizations by means of the Internet (Boyd and Ellison, 2007; Ellison et al., 2007; Kang and Lee, 2010; Kaplan and Haenlein, 2010; Pempek et al., 2009). SM supplies a new approach of communicating, utilizing PCs as a collaborative means to accelerate group constitution and intensification group extent and leverage (Kane et al., 2009). Hence, Pai and Arnott (2013) stated that a SM as Web based technologies that allow to create a virtual portrayal (profile) of a user or organization to constitute connections with other users and organizations for communications.

Based on author's review of existing scientific literature on social media, few empirical studies have been conducted to scientifically evaluate and explain the usage behavior of social media in context of SMEs. The present study fills the existing research gap by developing a new research model used for the assessment of SMEs' adoption of SM, which is a relevant undertaking that will make a valuable contribution to both science and organizations (Jussila et al., 2014; Leonardi, 2014; Malik et al., 2016; Wu, 2013). Due to their primary inception, social media (SM) has been gaining a significant quantity of community notice, to prompt of having millions of registered users and a billion hits per day (Agarwalet al., 2008; Kane et al., 2012; Kim et al., 2010). TAM, as one of the most common models, was proposed by Davis (1986) and Davis (1989) and it is an adaptation of the theory of reasoned action (Fishbein and Ajzen, 1975). It is well-established as a powerful and robust model for predicting user adoption of new technology like social media (Davis et al, 1989; Doll and Torkzadeh, 1988; Venktatesh and Davis, 2000; Zhang, Zhu and Liu, 2012).

While most studies so far have investigated the consumer side of social media adoption, the company adoption of social media remained largely under-researched (Jussila, Kärkkäinen, and Aramo-Immonen 2014; Michaelidou, Siamagka, and Christodoulides 2011). This study addresses this gap and contributes to literature mainly in two ways. The overall main aim of this study is two-fold: first, it aims to test the Technology Acceptance Model (TAM), Network Externality, and Innovation Diffusion Theory (IDT) and the TAM model and extend it to incorporate additional constructs from related literature in context of SM (Davis, 1986). In order to benefit professionals in developing best practices and researchers, who are interested in developing theories related to social media, researcher revisits and extends TAM (Davis, 1986) to explain organizational social media usage behavior. TAM has become so popular, because of fulfilling the theoretical attributes of being straight forward, supported by data, and being pertinent to predict adoption and usage of new technologies in respective disciplines (Hoof et al., 2005; Lee et al., 2003). To carry out the first aim, the fundamental sides of the TAM on social media is retained in the current study (Davis, 1986). However, TAM was developed based on the design of system traits and ignores to consider some distinguishing attributes of social media. Despite extensive research has examined the factors that lead people to adopt and use the SM through TAM (Lee, 2010; Shin, 2008; Shin, 2010; Shin and Kim, 2008; Willis, 2008). However, few 
approaches have focused on the influence of trust and perceived risk in this adoption process (Dwyer et al., 2007; Shin, 2010), since both variables are essential when uncertainty is present (Luhmann, 1979; Mayer et al., 1995), like the online environments. In the present paper the emphasis is to analyse the online consumer behaviour, hence its implications are applicable. Moreover, while this issue is of vital importance for better understanding the importance of SNS for theory and practice there is very little search based on data representing broad populations. Therefore, a second aim of current study is to revise the TAM model with additional constructs. To empirically investigate the new dimensions of TAM for a social media user proposed in the current study, used primary data collected from the SMEs users of social media. Based on the review of existing scientific literature on social media, few empirical studies have been conducted to scientifically evaluate and explain the usage behavior of social media using social media in context of Turkey. The proposed framework is tested within the context of Turkish SMEs addressing the lack of studies relating to social media adoption in emerging economies and SMEs. Turkey is a particularly active country in terms of social media usage and penetration. For example, it is the fourth largest country on Facebook in terms of number of profiles created and third country in terms of time spent per visit (Marketing Charts 2013; Social Bakers 2013). Driven by the significant online activity of Turkish consumers, many Turkish companies have started to adopt SM marketing. In addition, SMEs play a vital role in the Turkish economy; they comprise $98 \%-99 \%$ of all firms, represent $81 \%$ of all employment, and contribute $36 \%$ of the total gross domestic product (Kavcioglu, 2009). Consequently, Turkish SMEs constitute a good context for the investigation of social media adoption in SMEs. Although the situation is rapidly changing, scholars still have a limited understanding of acceptance of SNS. A validated instrument of usage behavior of social media can provide usability experts and practitioners with a validated tool to assess social media acceptance and usage behavior. This can help us gain a better understanding of who is and who is not using these sites, why, and for what purposes, especially in context of SMEs in Turkey. Such questions will require large-scale quantitative and qualitative research (Boyd and Ellison, 2007).

\section{Review of Literature and Hypotheses Development}

Very few studies have investigated at SM adoption from the aspect of SMEs (Lee, 2002; Simpson and Docherty, 2004). As previously mentioned, there is a shortage of studies examining the factors affecting the adoption especially in developing countries (Kawaljeet et al., 2014; Poorangi et al., 2013). With respect to its adoption in business contexts, a major part of the literature focuses on large enterprises (Meske and Stieglitz, 2013) and little research has been devoted to the study of social media adoption and use by SMEs.

Perhaps as a result of the lack of literature on social media adoption within the SMEs context (He, Wang and Zha, 2014; Durkin, McGowan and McKeown, 2013), little is known about why small firms engage in or avoid the use of such technologies (Beier and Wagner, 2014). The significance of social media to SMEs (Mannonen and Runonen, 2008) requires further investigation (He, Wang and Zha, 2014) and thus more research into the adoption and use of social media technology is needed (Aral, Dellarocas and Godes, 2013; Andzulis, Panagopoulos and Rapp, 2012; Constantinides, 2009; Kim, Lee and Lee, 2013). 
According to Nasco et al., (2008) the adoption of SM is very important to any economic system. Small and Medium-sized Enterprises (SMEs) are recognised as the backbone of any economy (Bahaddad, AlGhamdi and Houghton, 2012; Fong, 2011). SMEs play a major role in the national and global economy, and it is undeniable that they represent the highest percentage of organizations in almost all developed countries (Al-Mahdi, 2009). They play an important role in job creation as well as ensuring a country's economic stability. In fact, the Small and Medium-sized Enterprises are viewed as an essential component of modern industrialised societies (Rahayu and Day, 2015; Elasrag, 2011). Crucially, the utilization of SM is one of the latest examples of the vital role of technology in supporting and changing the business environment (Jagongo and Kinyua, 2013; Tapscott and Williams, 2007). SM is being considered as one of the effective mediums to reach target audiences of not just business organizations, but any governments, communities, or types of society (e.g. political or social) (Terblanche, 2011). Although many research studies have investigated SM and its significance to business, there is still only a vague understanding as to how SMEs can utilize SM adoption effectively (Durkin et al., 2013), particularly as SMEs may not have the budget nor the experience to copy international or large business approaches and strategies (Abed, 2015). Some SMEs tend to adopt a new technology, such as SM, for its perceived opportunities and to copy the market trend, yet do not have appropriate how-to-knowledge (Drury, 2008). Such under-utilization of technology might lead to problems in terms of ineffective adoption and results. Therefore, it is important to explore the impact of a new technology on SMEs as well as how to effectively adopt it in order to avoid any problematic implementation and results (Durkin et al.,2013). Therefore, SMEs need to prepare for SM adoption by extensively planning operations including finance, marketing, human-resource-management and production (Demirbas et al., 2011). Derham et al., (2011) and Constantinides et al., (2010) posit that SMEs can strongly benefit from using SM as it requires minimal cost, simple participation and low technological skills. Whereas Constantinides et al., (2010) suggest SM adoption can improve customer relations and business networks, Durkin et al., (2013) asserts that SMEs believe it is "a must" to adopt SM in business. Drew (2003) affirms that the "wait attitude" toward internet technologies adoption decision is no longer valid. As such these points support the argument that SM adoption is a necessary element for SMEs. For Dahnil et al (2014), the trend of social media usage by companies offers a clear research opportunity. For these authors, it is fundamental to understand the factors that support the adoption of social media marketing among companies. For Kuikka and Akkinen (2011), there is a vast literature, on a firm level, of barriers faced by organizations adopting a new enterprise system but very few studies specifically researched social media adoption and usage by companies. Moreover, before practical guidelines can be defined to support managers, overall social media adoption phenomenon needs to have more research and empirical evidence (Jobs \& Gilfoil, 2014).

On a broader perspective, the implementation of new internet-based technologies has been identified as a relevant process for moving a company toward electronic business. In this direction, business attitudes regarding the adoption of internet related innovation have been acknowledged as a critical factor for executing e-business strategy. There is limited research on business-level technology adoption when compared to research examining individual-level technology adoption ( $\mathrm{Yu} \& \mathrm{Tao}$, 2009). Similar results are indicated by Harris, Rae, and Grewal (2008). The authors 
surveyed 400 SME owner/managers in the United Kingdom by phone and case study 30 small firms that they categorize as early adopters using Web 2.0 in the form of blogs, RSS feeds, or online networking tools. Sinclaire and Vogus (2011), studied U.S. fast growing companies, the main factor for companies' adoption of social media was the mass adoption of social media by consumers. Michaelidou, Siamagka and Christodoulides (2011) researched social media adoption in the context of SMEs companies in the B2B space. The author identified five key barriers: lack of relevance of SNS within the industry the company operates in (a major challenge in this study, but may be very specific to B2B companies), uncertainty of benefits from using SNS, unfamiliarity and lack of technical skills of staff, large investment in terms of time and competitors do not use SNS. Similarly, Gligorijevic and Leong (2011) analyzed four small Australian companies using in-depth interviews and study how they utilize online consumer groups to connect to, communicate with, and maintain their customer base. Derham, Cragg, and Morrish (2011) and Stockdale, Ahmed, and Scheepers (2012) also highlighted the fact that SMEs are using SM for its interactive nature to facilitate information flow. Stockdale, Ahmed, and Scheepers (2012) investigated five SMEs in the United States from different industries that have successfully integrated more than one form of SM into their marketing strategy; resulting in $400 \%$ increase in website traffic, increase in revenues, and 70\% decrease in marketing expenses. Serra, Storopoli, Pinto and Serra (2013) identified that companies' social media adoption is facilitated by its easiness of access and the possibility to use it as selling benefit and client relationship channel in Latin America (Brazil). The same year, Kim, Lee, and Lee (2013) investigated why SMEs utilize social media with using as the three main drives SM, which includes networking, collaboration, and information sharing. And also, Durkin, McGowan, and McKeown (2013) choose an in-depth case analysis method with eight Irish SMEs to investigate the SMA process. As a recent study, Wamba and Carter (2014) assessed social media adoption by SMEs in context of both organizational and individual factors. Their results indicated that manager's age; firm size; innovativeness; and industry sector had a positive relation to adoption. In sum, the existing literature presents multiple angles over adoption factors and supporting theories that are employed to explain social media adoption.

Author drew upon three theories (TAM, Network Externality, and IDT) to develop a research model which explains why SMEs use SM (Figure 1). The proposed research model consists of eight constructs.

\section{Critical Mass (CM)}

In this study critical mass is defined as users of social media as the extent of the membership of people that matters most in a user's social media network. Extending the economic theory of positive externalities, the theory of $\mathrm{CM}$ states that once a certain number of users $(\mathrm{CM})$ have been, use and usage should spread rapidly throughout the community (Cameron and Webster, 2005). This user's group or the CM is responsible for collectively generating and exchanging information. Also, the psychological concept of social influence is rooted from the assumption that a person's behavior is heavily influenced by the behavior and presence of others. Therefore, the mass of users in social media connected to a user could be a critical component to explain the social media usage behavior. Therefore, a second objective of this study is to revise the Technology Acceptance Model (TAM), Network Externality, and Innovation Diffusion Theory (IDT) models with additional constructs, such as critical mass (CM) of a user that past literature have recognized as a significant factors influencing usage behavior of a 
technology. Author therefore propose: H1 "Critical Mass" has a positive significant effect on "Perceived Usefulness"

\section{Compatibility (COMP)}

Compatibility is defined as "the degree to which an innovation is perceived as consistent with the existing values, past experiences, and needs of potential adopters". SM provides many complementary services for users to enjoy in virtual worlds through various social applications (Lin and $\mathrm{Lu}, 2011$ ). In other words, compatibility may explain adoption on SM, where users want to reflect their lives into virtual sites. Thus, author put compatibility into the research model and hypothesized as below.

H2 "Compatibility" has a positive significant effect on "Perceived Usefulness"

\section{Perceived Usefulness (PU) and Intention to Use (IU)}

Perceived Usefulness is defined as "the degree to which a person believes that using a particular system would enhance his or her job performance the word from useful" (Davis, 1989). Many researches (e.g., Davis et al., 1989; Agarwal and Prasad, 1997; Venkatesh, 1999) have claimed that PU has a direct influence on the IU. TAM assumes that beliefs or attitudes about PU determine IU the technology which, then, leads to actual usage (Davis, 1989; Venktatesh and Davis, 2000). Furthermore, Lee et al. (2003) indicate that the relationship between the perceived usefulness and intention to use in the context of the TAM is statistically supported, since there are 74 studies that show a significant relationship between both variables. For this current study on social media, IU utilized as the continued intention to perform social media-related activities using the social media site (Fishbein and Ajzen, 1975). Further, actual use (AU) is defined in terms of the frequency of social media used by the user. The TAM model based the relationship of PU, IU, and AU from the TRA model (Ajzen and Fishbein, 1980). For this reason author considered PU as a construct in the research model and hypothesized as below.

H3 "Intention to use" has a positive significant effect on "Actual Use".

H6 "Perceived Usefulness" has a positive significant effect on "Intention to Use".

\section{Members (M)}

"Members" is defined as "the degree to which a person use particular technology or system because of other people's use (e.g., friends, family, and etc.)". This construct was derived from Network Externality

Theory. Sledgianowski and Kulviwat (2009) suggested that a user intend to use SM once its participants reach a significant number. In order to attract more users, SM provides users with the supporting tools such as social games, message function, page function, etc. (Lin and Lu, 2011). In other words, users can interact with each other actively using the supporting tool provided by SM. From the reason, "Members" was added to the research model and hypothesized as. H4 "Members" has a positive significant effect on "Perceived Usefulness"

\section{Perceived Ease of Use (PEU)}

Perceived ease of use is an important determinant of the use of technology or systems along with perceived usefulness in TAM (Davis 1989, Davis et al., 1992). Davis (1989) defined Perceived Ease of Use as "the degree to which a person believes that using a particular system would be free of effort the word from ease". This concept has been widely used to explain user's adoption to system (e.g., Davis et al., 1989; Agarwal and Prasad, 1997). Since many systems can be explained by PEU, author put 
PEU into the research model and expected that PU is a good predictive variable. In the context of social media, the user may assess the site based on how easy it is to use and how effective it is in helping them accomplish their social-media-related needs. To support such wide demographics of users on these social media sites, the design of modules, applications, and tools, needs to be user-centric. The importance of perceived ease of use has been reinforced in TAM because of the poor user interface impact on the rejection of the technology in IT (Venkatesh and Davis, 2000). The site needs a clear and simplistic overview of services, fluent navigation, and smooth user interaction. The social media site should be intuitive for the first time user, and should be efficient in getting tasks done. On the other hand, the ease of use can also be instrumental, contributing to increase the performance. This increase means less effort, thanks to the ease of use, allowing getting more work done with the same effort (Davis et al. 1992). Past studies (Rauniar et al., 2009; Molla and Licker, 2001; Yoo and Donthu, 2001; Zeithaml, 2000) indicate that an easy to use web site can enhance the user's experience. Most studies about TAM assume also that PEU is directly linked to PU (Davis, 1989; Nysveen et al., 2005a; Nysveen et al., 2005b). This instrumental effect on the attitude occurs via perceived usefulness, as the original TAM model postulates. Furthermore, this effect has been amply demonstrated in empirical studies (Davis 1989, Davis et al. 1989; Agarwal and Prasad 1997; Venkatesh 2000; Venkatesh and Davis 2000). In addition, Based on the original TAM, perceived ease of use have a positive significant effect on perceived usefulness, thus, author put the hypothesis H5 into the model. H5 "Perceived Ease of Use" has a positive significant effect on "Perceived Usefulness"

\section{Trustworthiness (TW)}

Trust, is one of the determinants of intention to use and the antecedents of perceived usefulness, especially in an online environment, which is a significant construct to the TAM model for social media. Social media is collecting information about a user's physical and social context, when a user create a profile on a SM. Therefore, the confidentiality of information and not to misuse of information are significant for users. A user intent to participate in a social media site with the CM fully and freely, user has not worries related to privacy or safety concerns. Trust plays a key role in new technology adoption because it impacts on users' intentions (Palvia, 2009; Gefen and Straub, 2003). In addition to the PU of social media, author suggests that IU social media will also be influenced by the extent to which the user finds such a social media site trustworthy. In summary, theories in social psychology, economics, and diffusion of innovations support the notion that a perceived CM is a key variable for new technology acceptance (Lou et al., 2000). Therefore: H7 "Trustworthiness" has a positive significant effect on "Intention to Use".

\section{RESEARCH METHOD}

\subsection{MEASURES OF THE CONSTRUCTS}

A structured questionnaire was developed to explore the various drivers of social media adoption. The survey was primarily developed in English language and then translated into Turkish. A pilot study was conducted with 48 social media users and two experts of information systems. Finally, a modified structured questionnaire was developed based on the pilot study and the opinions of the experts. Pilot test's respondents were not used in the further analysis. All constructs in the study involved multiple items. The items were measured using a five-point Likert-type scale for all constructs. 


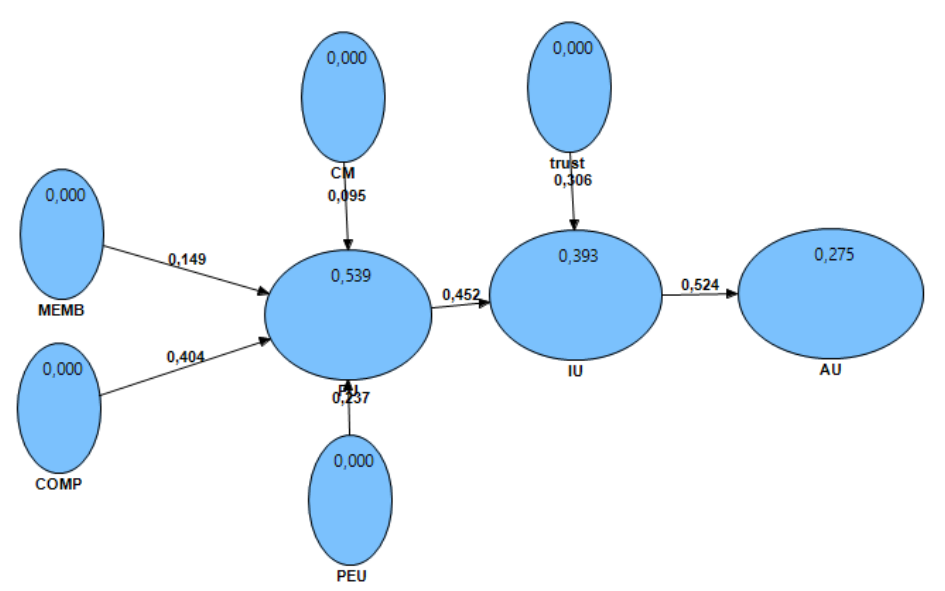

Figure 1. Proposed research model

In this study, the variables and scales to measure these constructs are adapted from prior researches to ensure the content validity of the scales. The measurement items of intention to use (IU), actual usage (AU), perceived ease of use (PEU) and perceived usefulness (PU) were adapted from (Davis, 1986; Davis, 1989; Mathieson, 1991; Moore and Benbasat, 1991; Taylor and Todd, 1995; Venkatesh and Davis, 1996). And the measurement items of Member (M) was adapted from Lin and Lu's (2011). The variables of Compatibility (COMP) construct was adapted from Wu and Wang (2005). Similarly, the measurement items of critical mass (CM) was adopted from the study Rouibah and Abbas (2006). The measurement items of trustworthiness (TW) was adapted from from Fogels and Nehmad (2009) and Telzrow et al. (2007).

The descriptive statistics of the sample showed that females account for 41.9 and males 58.1 percent of the social network users. Half of the respondents were between 21-30 years of age, the percent of 38.5 was in the age group below 20 years of age, 18 percent of respondents were $31+$ years of age. In this context, younger generation prefers to use social network websites compared to older age groups (30 years old above). In addition, majority respondents claimed that they use social network sites for one to five hours weekly ( 44 percent), followed by six to ten hours ( 21.5 percent), for eleven to fifteen hours weeky (14.9), fifteen hours above with 19.3 percent. The majority of respondents were high school degree and represented $40 \%$. followed by vocational school degree (32.1 percent), bachelor degree (18.2 percent), master and Ph.D. degree (9.7 percent). The respondent enterprises 18\% 0-1 years age, 1-3 years $\% 48,3-5$ years age, $\% 34$ more than 5 years age. The industry type of respondent enterprises $\% 30$ manufacturing, $\% 20$ wholesale and retail, $\% 10$ construction, $\% 40$ other sectors. The market scope of respondent enterprises $\% 80$ local, $\% 85$ national, $\% 18$ regional.

\subsection{DATA COLLECTION PROCESS}

To reach social media users, a web-based survey was used. It was decided that purposive sampling would be the most appropriate sampling strategy to be used in this phase of the research. However, later in the phase another sampling method, convenience, was used. At the beginning of the phase, the researcher made a list of the SMEs identified as promising candidates, using the criteria explained below. The candidates were approached via different means (including email, phone calls and social media), yet some were reluctant to participate and others decided not to participate. 
Considering the context of the study, SMEs in Turkey, it is essential that the key informants are the decision makers in those enterprises. In the SME setting, the literature suggests that business owner-managers are often responsible for the decisionmaking process. Therefore, recruiting participants from these well-informed and highstatus individuals as participants should ensure accurate and rich information and provide a clearer picture of social media adoption among Turkish SMEs. In both sampling methods, the identified candidates were contacted and provided with detailed information about the study and the participation process. In total, a group of $856 \mathrm{SMEs}$ were selected as potential candidates. The 856 SMEs were selected from different sectors and were expected to meet the following sampling criteria: SMEs should be registered and classified as SMEs with the Chamber of Commerce and Industry. If possible, selected enterprises should belong to different sectors. This condition was perceived as important because including enterprises that operate in different sectors would lead to richer data than limiting the sample to a single sector. Selected enterprises should have a presence on at least one social media platform. This criterion was used as the study was interested in determining factors that influence the adoption of social media among SMEs.

Determining a right sample size is very crucial for ensuring quality and rigour of any study. For this purpose, Hair et al. (2017:20) have suggested the use of 10 times rule, which was proposed by Barclay et al. (1995) for determining minimum sample size in a PLS-SEM analysis. This rule states that minimum sample should be " 10 times the largest number of structural paths directed at a particular construct in structural model". Structural model of this study involves eight constructs (i.e. seven independent and one dependent variable) and according to this 10 times rule criterion, our minimum sample size should be 80 respondents. However, author has adopted a more rigorous criterion proposed by Westland (2010). A total of 546 surveys were collected from the participants, of which 473 were found to be usable in the data analysis. These valid responses were analyzed to assess reliability, validity, and appropriateness for hypotheses testing.

\subsection{DATA ANALYSIS AND RESULTS}

This study utilizes the Structural Equation Modeling (SEM) approach with Partial Least Square (PLS) as a second generation multivariate analytical tool using SmartPLS 2.0 M3 (Fornell and Larcker, 1981; Hair et al., 2012; Ringle et al., 2005; Ringle, Sarstedt, \& Straub, 2012; Ringle et al., 2015; Wong, 2013). In this study, Hair et al.'s (2014a) four-step approach is utilized to measure structural model. (1) the assessment of the significance of the path coefficients, (2) the test of the level of the $R^{2}$ value, (3) the measurement of the $f^{2}$ effect size, and (4) the evaluation of the prediction relevance $\left(\mathrm{q}^{2}\right)$. The Structural model has been assessed based on the $\mathrm{R}^{2}$ for the endogenous variables (Henseler et al., 2009; Tenenhaus, Vinzi, Chatelin, \& Lauro, 2005). The details of each step appear below. Furthermore, the structural model (complete) was assessed by applying a two-stage approach (Anderson \& Gerbing, 1988; Henseler, Ringle, and Sinkovics, 2009) using SmartPLS 2.0 M3 (Ringle et al., 2005). The first step the measurement model was examined to test the reliability and validity of constructs using 
the structural model, then the second step was utilized the structural model and hypotheses (Henseler, Ringle, and Sinkovics, 2009).

\subsection{EVALUATION OF THE MEASUREMENT MODEL}

First, the reliability and validity of the measurement instrument assessed by means of content validity, reliability and convergent validity criteria. All the results of these criteria are presented in Table 1.

The composite and indicator reliabilities are better options with acceptable loadings of above 0.70 and 0.60 , respectively. In addition, convergent validity with the average variance extracted (AVE) higher than 0.50 is equally acceptable. The current instrument met all these criteria (Bagozzi and Yi, 1988; Hair et al., 2011; Hair et al., 2013; Wong, 2013) and Cronbach's alpha (Nunnally and Bernstein, 1994), respectively. The reliability of all items was identified using Cronbach's alpha. The reliability analysis showed a Cronbach's alpha greater than .73. According to Rovai et al. (2013), a Cronbach's alpha of .90 indicates high reliability, .70 to $<.90$ indicates high reliability, and .50 to $<.70$ indicates moderate reliability. The result of the reliability analysis shows that all items are within the acceptable range for reliability. Finally, discriminant validity is measured by examining the correlation between the measures of the potential overlapping constructs (Fornell \& Larcker, 1981). According to Compeau et al. (1999) the average variance shared between each construct and its measure should be greater than the variance shared between the constructs and other constructs. The results for discriminant validity analysis showed that each indicator's outer loading on the associated construct was greater than all of its loadings on other constructs that the measure is discriminant (Hair et al., 2011; Wong, 2013). The result for discriminant validity is presented in Table 1 below.

Table 1. Evaluation of the reflective measurement model.

\begin{tabular}{|c|c|c|c|c|c|c|c|c|c|c|c|c|}
\hline & & & & & Inter- & onstru & correlati & & & & & \\
\hline $\mathrm{LC}$ & $\begin{array}{l}\text { Range of } \\
\text { factor } \\
\text { loadings }\end{array}$ & $\mathrm{CR}^{\mathrm{a}}$ & $A^{b}$ & $\mathrm{AVE}^{\mathrm{c}}$ & $\mathbf{A U}$ & $\mathbf{C M}$ & COMP & IU & МЕМВ & PEU & PU & TRUST \\
\hline $\mathbf{A U}$ & $\begin{array}{l}0.755- \\
0.851\end{array}$ & 0,85 & 0,73 & 0,65 & 1 & & & & & & & \\
\hline CM & $\begin{array}{l}0.794- \\
0.852\end{array}$ & 0,87 & 0,76 & 0,68 & 0,46 & 1 & & & & & & \\
\hline COMP & $\begin{array}{l}0.837- \\
0.897 \\
\end{array}$ & 0,90 & 0,83 & 0,74 & 0,56 & 0,44 & 1 & & & & & \\
\hline IU & $\begin{array}{l}0.791- \\
0.866 \\
\end{array}$ & 0,87 & 0,78 & 0,69 & 0,53 & 0,53 & 0,58 & 1 & & & & \\
\hline МЕMB & $\begin{array}{l}0.855- \\
0.910 \\
\end{array}$ & 0,91 & 0,85 & 0,77 & 0,26 & 0,55 & 0,50 & 0,40 & 1 & & & \\
\hline PEU & $\begin{array}{l}0.807- \\
0.851 \\
\end{array}$ & 0,91 & 0,86 & 0,70 & 0,36 & 0,45 & 0,61 & 0,43 & 0,64 & 1 & & \\
\hline PU & $\begin{array}{l}0.824- \\
0,864 \\
\end{array}$ & 0,89 & 0,81 & 0,72 & 0,44 & 0,46 & 0,67 & 0,56 & 0,55 & 0,62 & 1 & \\
\hline TRUST & $\begin{array}{l}0.755- \\
0.894\end{array}$ & 0,91 & 0,87 & 0,71 & 0,38 & 0,29 & 0,47 & 0,47 & 0,27 & 0,35 & 0,35 & 1 \\
\hline
\end{tabular}

${ }^{a}$ Composite reliability $(\mathrm{CR})=($ square of the summation of the factor loadings)/\{(square of the summation of the factor

loadings $)+$ (square of the summation of the error variances $)\}$.

', Cronbach's alpha.

${ }^{c}$ Average variance extracted $(\mathrm{AVE})=($ summation of the square of the factor loadings $) /\{($ summation of the square of the factor loadings $)+$ (summation of the error variances $)\}$.

${ }^{\mathrm{d}}$ The square roots of the constructs' AVE values are shown in the diagonal line (in bold); non-diagonal elements are latent variable correlations. 
Table 2. Results of hypothesis testing and predictable power.

\begin{tabular}{|c|c|c|c|c|c|c|}
\hline Hypotheses and path & $\beta$ path coef. & $t$-value ${ }^{\mathrm{a}}$ & ${ }^{1} f^{2}$ & $\mathrm{R}^{2}$ & ${ }^{2} q^{2}$ & $\mathrm{Q}^{2}$ \\
\hline H1 CM -> PU & 0,095224 & $1,99 * *$ & 0,013015 & & 0,008199 & \\
\hline H2 COMP -> PU & 0,404355 & $8,42 * * *$ & 0,210412 & 0,54 & 0,112093 & 0.717 \\
\hline H3 IU -> AU & 0,525045 & $14,60 * * *$ & & 0,28 & & 0.301 \\
\hline H4 MEMB -> PU & 0,149245 & $3,18 * * *$ & 0,023861 & & 0,014039 & \\
\hline H5 PEU -> PU & 0,235957 & $4,21 * * *$ & 0,058568 & & 0,035207 & \\
\hline H6 PU -> IU & 0,452824 & $10,15 * * *$ & & 0,39 & & 0.686 \\
\hline H7 TRUST -> IU & 0,305490 & $7,59 * * *$ & 0,132013 & & 0,079563 & \\
\hline \multicolumn{7}{|c|}{ 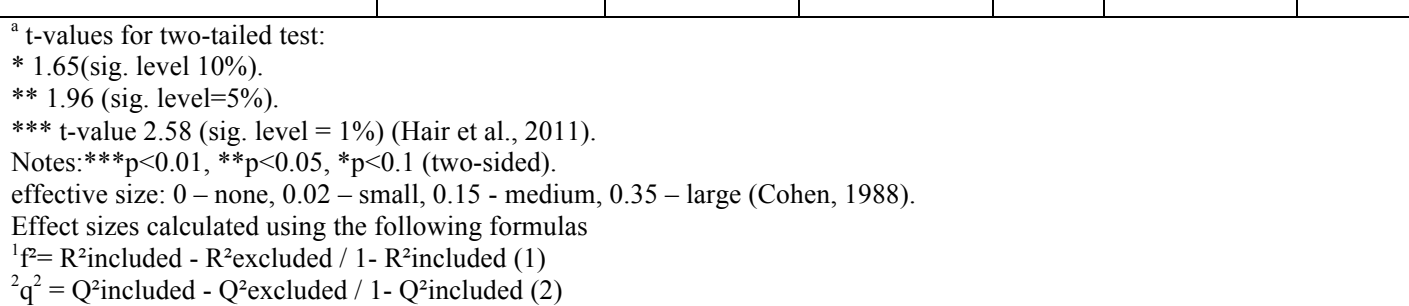 } \\
\hline
\end{tabular}

\subsection{EVALUATION OF THE STRUCTURAL MODEL}

The evaluation of reflective inner models involve the assessment of the coefficient of determination $\left(\mathrm{R}^{2}\right)$, path coefficients, predictive relevance $\left(\mathrm{Q}^{2}\right)$, and the effect size $\left(\mathrm{f}^{2}\right)$ (Hair et al., 2013). In addition, standard error was obtained using bootstrapping procedure was used 473 cases, 5000 samples to test the significance and the no sign changes option were selected to evaluate the significance of path coefficients and the strength of each path in the PLS model (Hair, Sarstedt, Ringle and Mena, 2012). The results of the structural model indicated that, as listed in Table 2, 7 hypothesized paths were statistically significant. Also, H1, H2 H3, H4, H5, H6 and H7 were supported.

The results of structural model showed that as the endogenous latent construct the $\mathrm{R}^{2}$ value for perceived usefulness is 0.539 with a $\mathrm{Q}^{2}$ value of 0.714 , which is relatively high. Intention to use $\mathrm{R}^{2}=0.394, \mathrm{Q}^{2}=0.710$, actual use $\mathrm{R}^{2}=0.276, \mathrm{Q}^{2}=0.300$ also show a large effect size. Thus, the explanatory power of perceived ease of use, critical mass, compatibility and members variables explained $\% 54$ of the variance in perceived usefulness is moderate. Perceived ease of use, perceived usefulness, critical mass, compatibility, members and trustworthiness variables explained $\% 39$ of the variance in intention to use is moderate. Perceived ease of use, perceived usefulness, critical mass, compatibility, members trustworthiness and actual use variables explained $\% 28$ of the variance in actual use is moderate. $\mathrm{R}^{2}$ values are described $0.67,0.33$ and 0.19 as substantial, moderate and weak, respectively (Chin, 1998; Henseler, Ringle, and Sinkovics, 2009). According to the guideline by Cohen (1988), the evaluation criteria for $\mathrm{R}^{2}$ range from 0 to 1 and values of $0.25,0.13$ or 0.02 present good, moderate, and weak levels, respectively, of predictive accuracy of the constructs in the model (Gaur and Gaur, 2006; Griffith, 1996). However, Hair et al. (2012) suggested that the judgment of $\mathrm{R}^{2}$ value is high/low depends on the specific research context. To evaluate the structural models' predictive power, $\mathrm{R}$ squares $\left(\mathrm{R}^{2}\right)$ were calculated. $\mathrm{R}$ squares $\left(\mathrm{R}^{2}\right)$ 
indicates the amount of variance explained by the exogenous variables (Barclay et al., 1995). The second step of the inner model evaluation involved the assessment of $Q^{2}$ (Hair et al., 2014a; Hair et al., 2014b; Wong, 2013). This procedure used the blindfolding in the PLS software (Henseler et al., 2012; Tenenhaus et al. 2005). It assessed the inner model's predictive relevance (Hair et al., 2014b; Henseler et al., 2009). the assessment of $Q^{2}$ based on the Stone-Geisser's $Q^{2}$ can be applied for the predictive sample reuse technique can be applied as a criterion for the predictive relevance besides looking at the magnitude of the $\mathrm{R}^{2}$ (Geisser, 1975; Stone, 1974; Hair et al., 2014a; Wong, 2013). This procedure used the blindfolding in the PLS software (Henseler et al., 2012). It assessed the inner model's predictive relevance (Hair et al., $2014 b) . Q^{2}$ value greater than zero indicates the path model's predictive relevance for that construct, which depicts the path model's predictive relevance for that construct, which supports the model's (Fig.1) predictive relevance for the seven endogenous constructs. (Geisser, 1974; Hair, Ringle, and Sarstedt, 2011; Hair et al., 2013; Henseler, Ringle, and Sinkovics, 2009; Rigdon, 2014; Stone, 1974; Wong, 2016).

The finally step of the inner model assessment involved effect size $\left(f^{2}\right)$ evaluation, which shows the impact of a specific predictor construct on an endogenous latent construct, and the $\mathrm{q}^{2}$ effect size for the predictive relevance are presented in Table 2. Besides measuring the values of $R^{2}$ and $Q^{2}$, the literature further suggests evaluating both effect size $\mathrm{f}^{2}$ and $\mathrm{q}^{2}$ for the $\mathrm{R}^{2}$-values and $\mathrm{Q}^{2}$-values, respectively. Whereas the effect size is the practical significant contribution each of the latent variables, the effect size $\mathrm{q}^{2}$ evaluates the predictive relevance of the exogenous variables for a certain endogenous variable (Hair et al., 2013; Hair, Ringle, and Sarstedt, 2011). In order to determine these effect sizes, Chin (1998) and Henseler, Ringle, and Sinkovics (2009) define values of $0.02,0.15$ and 0.35 , which indicate small, medium and large effects, respectively. Considering the underlying research model, the exogenous variable $\mathrm{CM}$ has small effect size on endogenous variable PU $\left(f^{2}=0,013015\right)$ and COMP has medium effect size on PU $\left(f^{2}=0,210412\right)$. Meanwhile, all other $\mathrm{f}^{2}$-values constitute small effect size.

The $\mathrm{q}^{2}$-value of 0,112093 for the variable COMP determines small effect on the predictive relevance for $\mathrm{PU}$ in terms of the prediction relevance of individual exogenous variables. For all other $\mathrm{q}^{2}$-values, the analysis reveals a weak contribution for the prediction relevance. Table 2 presents an overview of all relevant criteria for assessing the quality of the structure model.

An important part of the model evaluation is the examination of fit indexes reflecting the predictive power of the estimated inner and outer model relationships. The goodness-of-fit (GoF) represents an operational solution to this problem as it is meant as an index for validating the PLS globally. A general criterion for evaluating GoF is to calculate the geometric mean of the average communality and the average $\mathrm{R}^{2}$. The

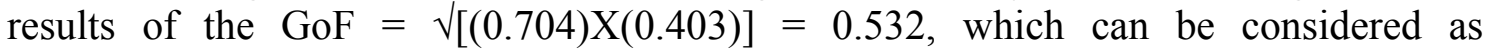
satisfactory (Tenenhaus, Vinzi, Chatelin, \& Lauro, 2005). GoF (0.53) observed is greater than the 0.36 recommended by the research of Wetzels et al. (2009). Wetzels, Odekerken-Schröder, and Van-Oppen (2009) recommended threshold values of the effect of the $\mathrm{GoF}$ as small $(\mathrm{GoF}=0.1)$, medium $(\mathrm{GoF}=0.25)$, and large $(\mathrm{GoF}=0.36)$. 


\section{DISCUSSION AND CONCLUSION}

This study has contributed to the understanding as well as to the limited knowledge on social media adoption, as it has examined the adoption of these technologies using a mixed method approach, in a highly important type of businesses, SMEs, in a context with limited studies, namely developing countries context.

A revised TAM framework was proposed and used for enhancing in order to have a better understanding of a social media user's attitudes toward usage factors that influence the adoption of social media by SMEs. The Research model was developed based on TAM, Network Externality and IDT. The proposed model consists of eight constructs; Perceived Usefulness (PU), Perceived Ease of Use (PEU), Members (M), Compatibility (C), critical mass (CM), trustworthiness (TW), intention to use (IU) and Actual Use (AU). PU, PEU, M, TW, CM and C affect the AU significantly and positively by using PLS as a statistical package as well as that the results of this study are usable and reasonable. As these new technologies are gaining popularity and wide acceptance among businesses, it is believed the research into the adoption and implementation of these technologies will become increasingly important. It can be said, therefore, that this study is a step in that direction as it had an exploratory objective to generate a comprehensive picture about social media adoption among SMEs in Turkey.

There are limitations to this current study. First of all, our results are based on small set of interviews ( $\mathrm{n}=473$ ), thus cannot be extrapolated to apply to all companies in the process of adopting and using social media. The interviewees were also handpicked from the researcher professional network and may as such be biased. The limitation to generalise the findings and conclusions from studies using non-probability sampling methods such as purposive and convenient sampling has been argued by some early researchers and focus on a larger sample to validate our research model and to examine the differences among SMEs (Babbie, 2007; Ogah, 2013). There are many behavioral theories and variables to be assessed to improve the prediction of social media acceptance and usage behavior suggested by our revised TAM model. Future studies can help in determining other factors and extending our research model. Moreover, future studies can add more constructs such as self-efficacy, altruism, and etc. to consider other aspects and factors and extending current research model. It is believed that there are many research questions regarding the SMEs behavior on social media sites and we therefore encourage future researches to contribute in developing a better understanding of social media in context of Turkish SMEs. Despite these limitations, we remain confident that the current empirical study on the revised TAM model can be helpful for future researchers, practitioners, and educators in the area of social media. The authors intend to follow up on this research by extending the study with a quantitative phase of it to further explore the propositions and relations identified. Other potential interesting research topics include evaluating barriers to adopt in other group of organizations such as big business. 


\section{REFERENCES}

Abed, G.T. (ed.), (2015). The Palestinian Economy: Studies in Development Under Prolonged Occupation. Routledge, Oxon.

Agarwal, R., Gupta, A., Kraut, R., (2008). "The interplay between digital and social networks", Inf. Syst. Res., 19, 243-252.

Agarwal, P. and Prasad, J. (1997), "The role of innovation characteristics and perceived voluntariness in the acceptance of information Technologies", Decision Sciences, vol. $28,557-582$.

Ajzen, I. and Fishbein, M., (1980), Understanding Attitude and Predicting Social Behavior, Prentice-Hall, Edgewood Cliffs, NJ.

Al-Mahdi, H., (2009). Supporting SMEs by universities: an emprical study in Saudi Arabia towards building a conceptual model for best practices. BBS Doctoral Symposium, Brunel University.

Anderson, J.C., Gerbing, D., (1988). "Structural equation modeling in practice: A review and recommended two-step approach", Psychological Bulletin, 103, (3), 411-423.

Andzulis, J., Panagopoulos, N.G., Rapp, A., (2012). "A review of social media and implications for the sales process", Journal of Personal Selling \& Sales Management, 32, (3), 305-316.

Aral, S., Dellarocas, C., Godes, D., (2013). "Introduction to the Special Issue-Social Media and Business Transformation: A Framework for Research", Information Systems Research, 24, (1), 3-13.

Babbie, E., (2007). The practice of social research. (11thed). Belmont: Wadworth Cengage Learning.

Bagozzi, R. P., Y. Yi., (1988). "On the Evaluation of Structural Equation Models", Journal of the Academy of Marketing Science, 16, (1), 74-94.

Bahaddad, A.A., AlGhamdi, R., Houghton, L., (2012). "To What Extent Would E-mall Enable SMEs to Adopt E-Commerce?”, arXiv preprint arXiv:1211.2402.

Barclay, D., Higgins, C., Thompson, R., (1995). "The partial least squares (PLS) approach to causal modeling: Personal computer adoption and use as an illustration", Technology Studies, 2, (2), 285-324.

Barnes, N.G., Jacobsen, S., (2013). "Adoption of social media by fast growing companies: innovation amongst the Inc. 500", J. Mark. Dev. Compeitiveness, 7, $11-17$.

Beier, M., Wagner, K., (2014). "Individual and Corporate Decisions to Adopt Social Media: Perception of Risks and Benefits in Small Firms", Available at SSRN 2384900 , . 
Boyd, D.M. and Ellison, N.B., (2007). "Social network sites: definition, history, and scholarship", Journal of Computer-Mediated Communication, Vol.13, No.1, 210230.

Cameron, A.F. and Webster, J., (2005), "Unintended consequences of emerging communication technologies: instant messaging in the workplace", Computers in Human Behavior, Vol. 21 No. 1, 85-103.

Chin, W. W., (1998). The Partial Least Squares Approach to Structural Equation Modeling. In Modern Methods for Business Research, edited by G. A. Marcoulides, 295-358. London Lawrence Erlbaum Associates.

Cohen, J., (1988). Statistical Power Analysis for the Behavioral Sciences. HillsDale, NJ: Lawrence Erlbaum.

Compeau, D., Higgins, C. A., Huff, S., (1999). "Social cognitive theory and individual reactions to computing technology: A longitudinal study", MIS quarterly, 145158.

Constantinides, E., (2009). Social Media/Web 2.0 as marketing parameter: An introduction, Proceedings of 8th International Congress Marketing Trends.

Constantinides, E., Lorenzo-Romero, C., Gómez, M.A., (2010). "Effects of web experience on consumer choice: a multicultural approach", Internet Res., 20, 188209.

Correa, T., Hinsley, A. W., de Zuniga, H. G., (2010). "Who interacts on the web? The intersectionof users' personality and social media use", Computers in Human Behavior, 26, 247-253.

Dahnil, M. I., Marzuki, K. M., Langgat, J., Fabeil, N. F., (2014). "Factors Influencing SMEs Adoption of Social Media Marketing", Procedia - Social and Behavioral Sciences, 148, 119-126.

Davis, F. D., Bagozzi, R. P., Warshaw, P. R., (1989). "User acceptance of computer technology: A comparison of two theoretical models", Management Science, 35, (8), 982-1003.

Davis, F.D., (1986). A technology acceptance model for empirically testing new enduser information systems: theory and results. Unpublished doctoral dissertation, MIT Sloan School of Management, Cambridge, MA.

Davis, F.D., (1989). "Perceived usefulness, perceived ease of use, and user acceptance of information Technologies", MIS Quarterly, 13, 2, 319-340.

Davis, F.D., Bagozzi, R.P. and Warshaw, P.R., (1992), "Extrinsic and intrinsic motivation to use computers in the workplace", Journal of Applied Social Psychology, Vol. 22 No. 14, 111-1132.

Demirbas, D., Hussain, J.G., Matlay, H., (2011), “Owner-managers' perceptions of barriers to innovation: empirical evidence from Turkish SMEs", J. Small Bus. Enterp. Dev., 18, 764-780

Derham, R., P. Cragg, Morrish, S., (2011). Creating value: An SME and social media. In PACIS 2011 Proceedings, Paper 53, Brisbane, Australia, July 7-11. 
Doll, W.J., Torkzadeh, G., (1988). "The measurement of end-user computing satisfaction", MISQuarterly, 12, 2, 258-274.

Drew, S., (2003). "Strategic uses of e-commerce by SMEs in the east of England", Eur. Manage. J., 21, 79-88.

Drury, G., (2008). "Social media: should marketers engage and how can it be done effectively?”, J. Direct Data Digit. Mark. Pract., 9, 274-278.

Durkin, M., P. McGowan, McKeown, N., (2013). "Exploring social media adoption in small to medium-sized enterprises in Ireland", Journal of Small Business and Enterprise Development, 20, (4), 716-734.

Dwyer, C., Hiltz, S.R., Passerini, K., (2007). Trust and privacy concern within social networking sites. Proceedings of the Thirteenth Americas Conference on Information Systems, Keystone, CO, USA.

Elasrag, H., (2011). "Enhancing the competitiveness of the Arab SMEs", Available at SSRN 1586454. http://papers.ssrn.com/sol3/papers.cfm?abstract_id=1586454

Ellison, N.B., Steinfield, C. and Lampe, C., (2007). "The benefits of Facebook 'friends': social capital and college students use of online social network sites", Journal of Computer-Mediated Communication, 12, 4, 1143-1168.

Fishbein, M. and Ajzen, I., (1975). Beliefs, Attitudes, Intention, and Behavior: An Introduction of Theory and Research. Addison-Wesley, Reading, MA.

Fogels, J., Nehmad, E., (2009). "Internet social network communities: risk taking, trust, and privacy concerns", Computers in Human Behavior, 25, 1, 153-160.

Fong, M.W., (2011). "Chinese SMEs and information technology adoption”, Informing Science and Information Technology, 8, 313-322.

Fornell, C., Larcker, D. F., (1981). "Evaluation Structural Equation Models with UnobservableVariables and Measurement Error", Journal of Marketing Research, $18,(1), 39-50$.

Gaur, A. S., Gaur, S. S., (2006). Statistical methods for practice and research: A guide to data analysis using SPSS. Sage.

Gefen, D. and Straub, D., (2003), "Managing user trust in B2C e-services", E-service Journal, vol. 2, no. 2, 7-24.

Geisser, S., (1974). "A Predictive Approach to the Random Effect Model”, Biometrika, 61, (1), 101-107.

Geisser, S., (1975). "The predictive sample reuse method with applications", Journal of the American Statistical Association, 70, (350), 320-328.

Gligorijevic, B., Leong, B., (2011). Trust, reputation and the small firm: Building online brand reputation for SMEs. In Proceedings of the Fifth International AAAI Conference on Weblogs and Social Media, ICWSM 11, Barcelona, Spain, July $17-21$.

Griffith, D. A., (1996). "Some guidelines for specifying the geographic weights matrix contained in spatial statistical models", Practical Handbook of Spatial Statistics, 65-82. 
Hair, J. F., C. M. Ringle, Sarstedt, M., (2011). "PLS-SEM: Indeed a Silver Bullet", Journal of Marketing Theory and Practice,18, (2), 139-152.

Hair, J. F., M. Sarstedt, C. M. Ringle, J. A. Mena, (2012). “An Assessment of the Use of PartialLeast Squares Structural Equation Modeling in Marketing Research", Journal of the Academy ofMarketing Science, 40, (3), 414-433.

Hair, J. F., G. T. M. Hult, C. M. Ringle, M. Sarstedt, (2013). A Primer on Partial Least Squares Structural Equation Modeling (PLS-SEM). 1st ed. Thousand Oaks, CA: Sage.

Hair, J. F., Hult, G. T. M., Ringle, C. M., Sarstedt, M., (2014a). A primer on partial least squares structural equation modeling (PLS-SEM). Thousand Oaks, CA: Sage Publications, Inc.

Hair, J. F., Sarstedt, M., Hopkins, L., Kuppelwieser, V. G., (2014b). "Partial least squares structural equation modeling (PLS-SEM): An emerging tool in business research”, European Business Review, 26 (2), 106-121.

Hair, J.F., Hult, G.T.M., Ringle, C., Sarstedt, M., (2017). A Primer on Partial Least Squares Structural Equation Modeling (PLS-SEM), second ed. Sage Publications Limited Inc, London, Thousand Oaks, Calif.

Harris, L., A. Rae, Grewal, S., (2008). "Out on the pull: How small firms are making themselves sexy with new online promotion techniques", International Journal of Technology Marketing, 3, (2), 153-168.

He, W., Wang, F., Zha, S., (2014), "Enhancing social media competitiveness of small businesses: insights from small pizzerias", New Review of Hypermedia and Multimedia, 20, (3), 225-250.

Henseler, J., Ringle, C. M., Sinkovics, R. R., (2009). The Use of Partial Least Squares Path Modeling inInternational Marketing. In R. R. Sinkovics, \& P. N. Ghauri (Eds.), Advances in International Marketing (Vol. 20, pp. 277-320). Bingley: Emerald.

Henseler, J., Ringle, C. M., Sarstedt, M., (2012). Using partial least squares path modeling in advertising research: Basic concepts and recent issues. Handbook of Research on International Advertising. Cheltenham: Edward Elgar Publishing.

Hoffman, D. L., T. P. Novak, (1996). "Marketing in hypermedia computer-mediated environments: Conceptual foundations", Journal of Marketing, 60, 50-68.

Hoof, B., Groot, J., Jonge, S., (2005). "Situational influence on the use of communication technologies: a meta-analysis", Journal of Business Communication, 42, i, 1.

Jagongo, A., Kinyua, C., (2013). “The social media and entrepreneurship growth”, Int. J. Humanit. Soc. Sci., 3, 213-227.

Jobs, C. G., Gilfoil, D. M., (2014). “A Social Media Advertising Adoption Model for Reallocation of Traditional Advertising Budgets", Academy of Marketing Studies Journal, 18, (1), 235-249. 
Jussila, J., Kärkkäinen, H., Aramo-Immonen, H., (2014). "Social media utilization in business-to-business relationships of technology industry firms", Comput. Hum. Behav.,30, 606-613.

Kane, G. C., Fichman, R. G., Gallaugher, J., Glaser, J., (2009). “Community relations 2.0.”, Harvard Business Review, 87, 45-50.

Kane, G., Alavi, M., Labianca, G., Borgatti, S., (2012). "What's different about social media networks? A framework and research agenda", MIS Quart.

Kang, Y. S., Lee, H., (2010). "Understanding the role of an IT artifact in online service continuance: An extended perspective of user satisfaction", Computers in Human Behavior, 26, 353-364.

Kaplan, A.M., Haenlein, M., (2010). "Users of the world, unite! The challenges and opportunities of social media. Business Horizons", 53, 1, 59-68.

Kavcioglu, S., (2009. The Turkish experience in SME finance and non-financial services streamlining. In SMEs in the Globalized World Conference, Istanbul, Turkey, April 9-10.

Kawaljeet, K., Dwivedi, Y.K., Williams, M., (2014). "Rogers' innovation adoption attributes: a systematic review and synthesis of existing research", Inf. Syst. Manage., 31, 74-91.

Kim, H.D., Lee, I., Lee, C.K., (2013), "Building Web 2.0 enterprises: A study of small and medium enterprises in the United States", International Small Business Journal, 31, (2), 156-174.

Kim, W., Jeong, O., Lee, S., (2010). “On social Web sites”, Inform. Syst., 35, 215-236.

Kuikka, M., Akkinen, M., (2011). Determining the Challenges of Organizational Social Media. In European Conference on Information Systems (ECIS) .

Lee, J., (2002). "Adoption of information technology in small business: testing drivers of adoption for entrepreneurs", Entrue J. Inf. Technol., 1, 21-36.

Lee, M., (2010). The effect of cognitive absorption and network externalities on technology acceptance: an empirical study of social networking sites in Indonesia. Unpublished Doctoral Dissertation, University of Ming Chuan, Taipei.

Lee, Y., Kozar, K.A., Larsen, K.R.T., (2003). "The technology acceptance model: past, present, and future", Communication of the Association for Information System, $12,1,752-780$.

Leonardi, P., (2014). "Social media, knowledge sharing, and innovation: toward a theory of communication visibility", Inform. Syst. Res.,25, 796-816.

Lin, K., Lu, H., (2011). "Why people use social networking sites: An empirical study integrating network externalities and motivation theory", Computer in Human Behavior, 27, 1152-1161.

Lou, H., Luo, W. and Strong, D. (2000), "Perceived critical mass effect on groupware acceptance", European Journal of Information Systems, Vol. 9 No. 2, 91-103.

Luhmann, N., (1979). Trust and power. Wiley, London 
Malik, A., Dhir, A., Nieminen, M., (2016). "Uses and Gratifications of digital photo sharing on Facebook", Telemat. Inform., 33, 129-138.

Marketing Charts, (2013). Social networking eats up 3+ hours per day for the average American user. http://www.marketingcharts.com/wp/Online/social-networkingeats-up-3-hours-per-day-for-the-average-american-user-26049/.

Mathieson, K., (1991). "Predicting user intentions: Comparing the technology acceptance model with the theory of planned behavior", Information Systems Research, 2, 173-191.

Mayer, R.C., Davis. J.H. and Schoorman, F.D., (1995). "An integrative model of organizational trust”, Acad Manag Rev., 20, (3), 709-734

Meske, C., Stieglitz, S., (2013). Adoption and use of social media in small and mediumsized enterprises', pp. 61-75, in Practice-Driven Research on Enterprise Transformation. Springer.

Michaelidou, N., N. Siamagka, G. Christodoulides., (2011). "Usage, barriers and measurement of social media marketing: An exploratory investigation of small and medium B2B brands", Industrial Marketing Management, 40, (7), 1153-1159.

Molla, A. and Licker, P.S. (2001), "E-commerce systems success: an attempt to extend and respecify the DeLone and McLean model of IS success", Journal of Electronic Commerce Research, Vol. 2 No. 4, 1-11.

Moore, G. C., Benbasat, I., (1991). "Development of an instrument tomeasure the perceptions ofadopting an information technology innovation", Information Systems Research, Vol 2, No 3, 173-191.

Nasco, S.A., Toledo, E.G., Mykytyn, P.P., (2008). "Predicting electronic commerce adoption in Chilean SMEs", J. Bus. Res., 61, 697-705.

Nunnally, J. C., I. H. Bernstein, (1994). Psychometric Theory. 3rd ed. New York: McGraw-Hill.

Nysveen, H., Pedersen, P.E. and Thorbornsen, H., (2005a), "Explaining intention to use mobile chat services: moderating effects of gender", Journal of ConsumerMarketing, Vol. 22 No. 5, 247-256.

Nysveen, H., Pedersen, P.E. and Thorbornsen, H., (2005b), "Intention to use mobile services: antecedents and cross-service comparison", Journal of the Academy of Marketing Science, Vol. 33 No. 3, 330-346.

Pai, P., Arnott, D., (2013). "User adoption of social networking sites: eliciting uses and gratifications through a means-end approach", Comput. Hum. Behav., 29, 10391053.

Palvia, P., (2009) "The role of trust in e-commerce relational exchange: A unified model", Information \& Management, vol. 46, no. 4, 213-220.

Pempek, T. A., Yermolayeva, Y. A., Yermolayeva, S. L., (2009). “College students' social networking experiences on Facebook", Journal of Applied Developmental Psychology, 30, 227-238. 
Poorangi, M.M., Khin, E.W., Nikoonejad, S., Kardevani, A., (2013). "E-commerce adoption in Malaysian small and medium enterprises practitioner firms: a revisit on Rogers' model", Anais Acad. Bras. Ciên. 85, 1593-1604.

Powell, J., (2009). 33 Million people in the room: How to create, influence, and run a successful business with social networking. NJ: FT Press

Rahayu, R., Day, J., (2015). "Determinant Factors of E-commerce Adoption by SMEs in Developing Country: Evidence from Indonesia", Procedia - Social and Behavioral Sciences, 195, 142-150.

Rauniar, R., Rawski, G., Crumbly, G. and Simms, J., (2009), "C2C online auction website performance: buyer's perspective", Journal of Electronic Research, Vol. 10 No. 2, 56-75.

Rigdon, E. E., (2014). "Rethinking partial least squares path modeling: Breaking chains and forging ahead", Long Range Planning, 47, (3), 154-160.

Ringle, C. M., S. Wende, and A. Will. (2005). SmartPLS 2.0 (M3) Beta." http://www.smartpls.de

Ringle, C. M., Sarstedt, M., \& Straub, D. M., (2012). "Editor' s Comments: A Critical Look at the Use of PLS-SEM in MIS Quarterly", Management Information Systems Quarterly, 36, (1), iii-xiv.

Ringle, C. M., Wende, S., \& Becker, J. M. (2015). SmartPLS 3. Boenningstedt: SmartPLS GmbH.

Rouibah K., and Abbas H.. (2006). Modified Technology Acceptance Model for Camera Mobile Phone Adoption: Development and validation. Proceedings of the 17th Australian Conference on Information System, Adelaide, Australia December 5-7, 2006.

Rovai, A. P., Baker, J. D., Ponton, M. K., (2013). Social science research design and statistics: A practitioner's guide to research methods and IBM SPSS analysis. Chesapeake, VA: Watertree Press.

Ryan, P. K., (2011a). Introduction. In Social Networking. 1st ed. New York: The Rosen Publishing Group, Inc. 4.

Ryan, P. K., (2011b). What are social networks? In: Social Net-working. 1st ed. New York: The Rosen Publishing Group, Inc. 7-8.

Serra, B., Storopoli, J. E., Pinto, C. F., Serra, F. R., (2013). "Mídias Sociais e Negócios: Um Estudo Delphi”, Revista Ibero-Americana de Estratégia, 12, (1), 236-253.

Shin, D.H., (2008). "Applying the technology acceptance model and flow theory to Cyworld user behavior", Cyber Psychology and Behavior, 11, 4, 12-20.

Shin, D.H., Kim, W.Y., (2008). "Applying the technology acceptance model and flow theory to Cyworld user behavior: implication of the Web2.0 user acceptance", Cyber Psychology and Behavior, 11, 3, 378-82.

Shin, D.H., (2010). "The effects of trust, security and privacy in social networking: a security-based approach to understand the pattern of adoption", Interact Comput., $22,(5), 428-438$. 
Simpson, M., Docherty, A.J., (2004). "E-commerce adoption support and advice for UK SMEs", J. Small Bus. Enterp. Dev., 11, 315-328.

Sinclaire, J. K., Vogus, C. E., (2011). "Adoption of social networking sites: An exploratory adaptive structuration perspective for global organizations", Information Technology and Management, 12, (4), 293-314.

Sledgianowski, D. and Kulviwat, S., (2009), "Using social network sites: The effects of playfulness, critical mass and trust in a hedonic context", Journal of Computer Information Systems, vol. 49, 74-83.

Social Bakers, (2013). Turkey is Facebook world country no. 4. http://www.socialbakers.com/blog/207-turkey-is-facebook-world-country-no-4.

Stockdale, R., A. Ahmed, Scheepers, H., (2012). Identifying business value from the use of social media: An SME perspective. In PACIS 2012 Proceedings, Paper 169, Hochiminh City, Vietnam, July 11-15.

Stone, M., (1974). "Cross-Validatory Choice and Assessment of Statistical Predictions", Journal of the Royal Statistical Society, 36, (2), 111-147.

Tapscott, D., Williams, A., (2007). Wikinomics: How Mass Collaboration Changes Everything. Penguin, New York.

Tapscott, D., (2008). Grown up digital: How the next generation is changing your World. New York: McGraw-Hill

Taylor, S., Todd, P. A., (1995). "Understanding Information Technology Usage: A Test of Competing Models", Information Systems Research, 6, 144-176.

Telzrow, M., Meyer, B., Lenz, H., (2007). "Multichannel consumer perceptions", Journal of Electronic Commerce Research, 8, 1, 18-31.

Tenenhaus, M., Vinzi, V. E., Chatelin, Y.-M., Lauro, C., (2005). "PLS path modeling", Computational Statistics and Data Analysis, 48(1), 159-205.

Terblanche, N.S., (2011). "You cannot run or hide from social media - ask a politician", J. Public Aff. 11, 156-167.

Venkatesh, V., Davis, F. D., (1996). "A model of the antecedents of perceived ease of use: Development and test", Decision Sciences, 27, (3), 451-481.

Venkatesh, V., (1999), "Creation of favorable uses perceptions: Exploring the role of intrinsic motivation", MIS Quarterly, vol. 23, 239-260.

Venktatesh, V., Davis, F.D., (2000). "A theoretical extension of the technology acceptance model: four longitudinal field studies", Management Science, 46, 2, 186-204.

Wamba, S. F., Carter, L., (2014). "Social media tools adoption and use by SMEs: An empirical study", Journal of Organizational and End User Computing, 26, (2), 116.

Westland, J.C., (2010). "Lower bounds on sample size in structural equation modeling", Electron. Commer. Res. Appl. 9, 476-487. 
Wetzels, M., Odekerken-Schroder, G. Oppen, C.V., (2009). "Using PLS path modeling for assessing hierarchical construct models: guidelines and empirical illustration", MIS Quarterly, 33, 1, 177-195.

Willis, T.J., (2008). An evaluation of the technology acceptance model as a means of understandingonline social networking behavior. Unpublished doctoral dissertation, University of South Florida, Tampa, FL.

Wong, K. K. K., (2013). "Partial least squares structural equation modeling (PLS-SEM) techniques using SmartPLS", Marketing Bulletin, 24, 1-32.

Wong, K. K. K., (2016). "Technical note: Mediation analysis, categorical moderation analysis, and higher-order constructs modeling in partial least squares structural equation modeling (PLS-SEM): A B2B Example using SmartPLS", Marketing Bulletin, 26, 1-22.

Wu, J. H., Wang, S. C., (2005). "What drives mobile commerce? An empirical evaluation of the revised technology acceptance model", Information Management, 42, 719-729.

Wu, L., (2013). "Social network effects on productivity and job security: evidence from the adoption of a social networking tool", Inform. Syst. Res., 24, 30-51.

Yoo, B. and Donthu, N., (2001), "Developing a scale to measure the perceived quality of an internetshopping site (SITEQUAL)", Quarterly Journal of Electronic Commerce, Vol. 2 No. 1, 31-45.

Yu, C. S., Tao, Y. H., (2009). "Understanding business-level innovation technology adoption", Technovation, 29, (2), 92-109.

Zeithaml, V.A., (2000), "Service quality, profitability, and the economic worth of customers: what we know and what we need to learn", Journal of the Academy of Marketing Science, Vol. 28 No. 1, 67-85.

Zhang, L., Zhu, J., Liu, Q., (2012). "A meta-analysis of mobile commerce and the moderating effect of culture", Computers in Human Behavior, 28, (5), 19021911.

Zhou, T., (2011). "Understanding online community user participation: a social influence perspective", Internet Research, 21, 1, 67-81. 